\title{
ANTERIOR CERVICAL DISCECTOMY AND FUSION
}

\author{
A Clinical and Biomechanical Study with Eight-year Follow-up* \\ Edward H. Simmons $\nmid$ and S. K. Bhalla, $\ddagger$ Toronto, Canada \\ with a note on \\ DISCOGRAPHY: TECHNIQUE AND INTERPRETATION OF RESULTS
}

\author{
W. P. Butt, Toronto, Canada \\ From the Toronto East General and Orthopaedic Hospital
}

The most important point to be emphasised in the handling of patients with mechanical disorders of the cervical spine is that operation is rarely required. However, a small percentage of patients become severely and chronically disabled by pain which is amenable to judicious operation.

Bailey and Badgley (1960) reported the use of anterior cervical fusion in 1952 in a twenty-one-year-old woman who had an extensive lytic lesion of the fourth and fifth cervical vertebrae. Cloward in 1958 and 1959 published the results of his series in which he had been employing this approach since 1953. His special instruments simplified the technique and did much to popularise the procedure. Robinson reported his use of the anterior approach since 1954 and the results of his technique (Robinson and Smith 1955; Robinson and Southwick 1960; Robinson, Walker, Ferlic and Wiecking 1962). Although some surgeons still prefer the posterior approach (Scoville 1966), the anterior approach for cervical discectomy and fusion has become a standard procedure and is used routinely in many centres. It has obvious advantages over the posterior operation in that it is an easier approach, the fusion rate is high and the post-operative management is simpler.

In the treatment of these patients there are three main considerations: the selection of the right patient, the selection of the right level or levels, and the selection of the right operation.

\section{SELECTION OF THE PATIENT}

This is the most important consideration. Patients who require operation often give a history of significant injury. They have a characteristic mechanical type of pain with constant aggravation by activity and usually by coughing or sneezing, with at least some improvement by rest, support and traction. These findings indicate a mechanical type of pain which, if sufficiently severe and persistent, is likely to be amenable to surgical treatment. All these patients should first have adequate conservative treatment.

The most important feature on clinical examination is consistency of complaints and physical findings. The physical signs usually include persistent limitation of movement, localised muscle tenderness in the distribution of a particular nerve root, localised interspinous tenderness, often with tenderness anteriorly at the same level, a localising neurological deficit

\footnotetext{
* Presented at the twenty-third annual meeting of the Canadian Orthopaedic Association at Montreal, Quebec, Canada, June 1967, and to the thirty-fifth annual meeting of the American Academy of Orthopaedic Surgeons (Audio-visual Program), Chicago, Illinois, U.S.A., January 21, 23, 24, 1968.

† Clinical Teacher in Orthopaedic Surgery, Department of Surgery, University of Toronto; Attending Orthopaedic Surgeon, Toronto East General and Orthopaedic Hospital; Consulting Orthopaedic Surgeon, Ontario Society for Crippled Children's Centre, Toronto, Canada.

$\ddagger$ Orthopaedic Surgical Research Fellow, Department of Orthopaedic Surgery, Toronto East General and Orthopaedic Hospital, Toronto, Ontario, Canada.
} 
and a positive vertical compression test. In the neurological assessment, lower trunk irritation from spasm of the scalenus anterior should not be confused with nerve root compression. Pain and numbness extending along the medial side of the limb into the ring and little fingers may occur with scalenus anterior spasm secondary to cervical spinal disorder.

\section{DETERMINATION OF LEVEL FOR FUSION}

Radicular pain or sensory change suggests the particular nerve root involved. Localised tenderness is helpful. Objective neurological findings may indicate the particular level.

Myelography is a useful screening test and may show posterior disc bulging and root sleeve compression (Fig. 1). In many cases it is not helpful and it can be misleading.

Despite the criticisms of cervical discography, we have found that when it is properly performed it is the most valuable single guide to the level of the causative lesion. To be of value it must be very skilfully done. It must be done with an image intensifier. The exact reproduction of the patient's pain at a particular level can be determined only if he is awake. The needles must be accurately placed in the nucleus pulposus and not in the annulus, because injection of the annulus itself is extremely painful in any disc (Fig. 2). If the contrast medium extravasates along the root sleeves it may produce irritation or pain and a false positive response. Therefore the initial injection should be done with saline, at least two

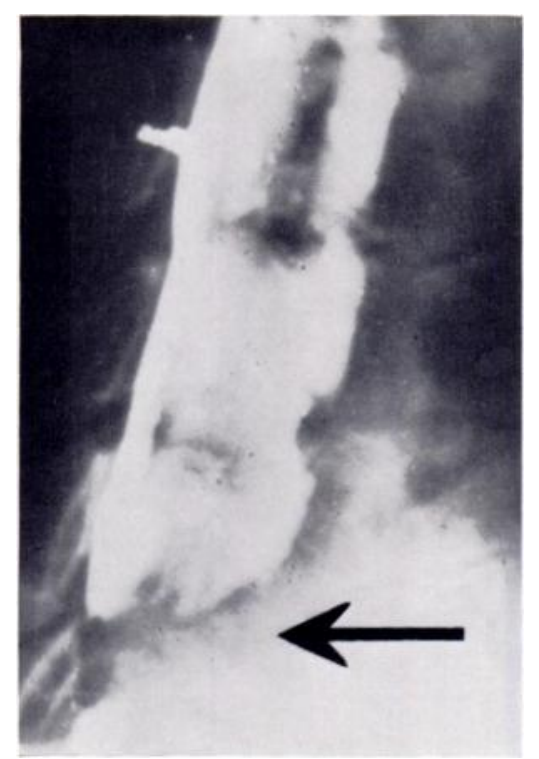

FIG. 1

FIGS. 1 AND 2

Figure 1-Cervical myelograph showing posterior disc bulging and root sleeve compression. Figure 2-Cervical discograph showing points of needles in centres of nuclei of the discs.

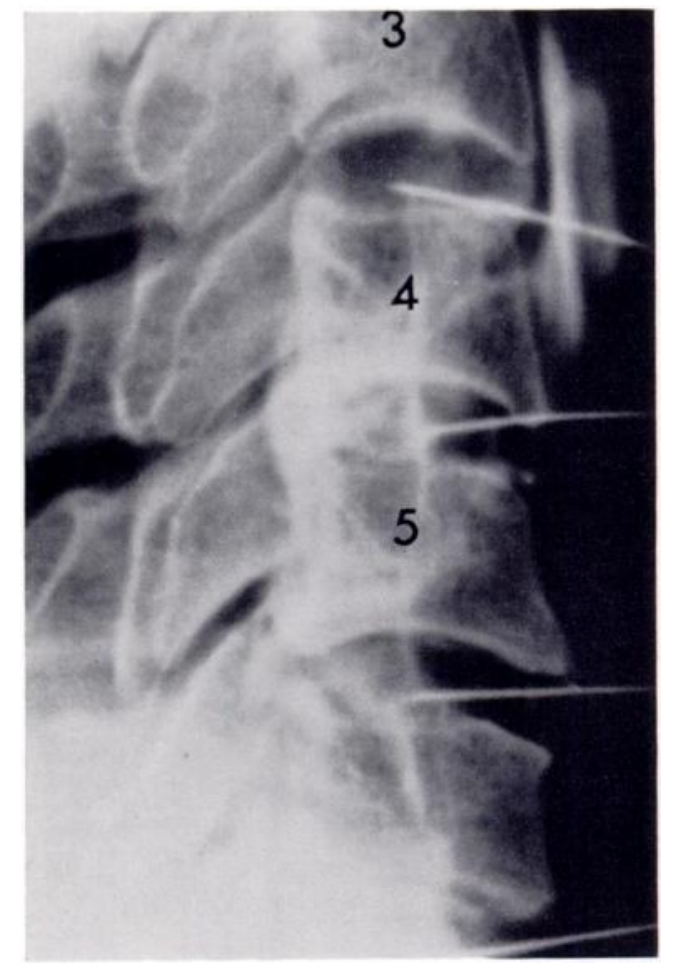

FIG. 2

injections being done at each level. The response should be confirmed by altering the order of disc injections without telling the patient and often by deliberately trying to confuse him with misleading questions. Only if the response is constant throughout these manoeuvres should the examination be accepted as diagnostic. When the subjective response has been thoroughly evaluated and recorded, the contrast material is injected. Discography in our cases has been the work of Dr W. P. Butt $(1963,1966)$. 


\section{ILLUSTRATIVE CASE REPORT}

Case 1-A fifty-eight-year-old woman had suffered injury to her neck two years previously. There was persistent severe neck pain with radiation towards the shoulders and severe occipital and sub-occipital headaches. She had not responded well to extensive out-patient treatment or to seven weeks' treatment in hospital. Radiographs showed advanced degeneration at all levels (Fig. 3). Myelography showed anterior bar formation between the fourth and fifth

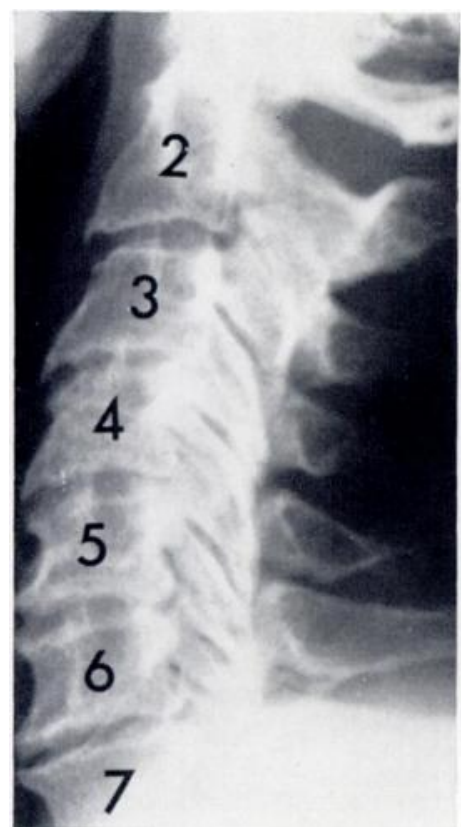

FIG. 3

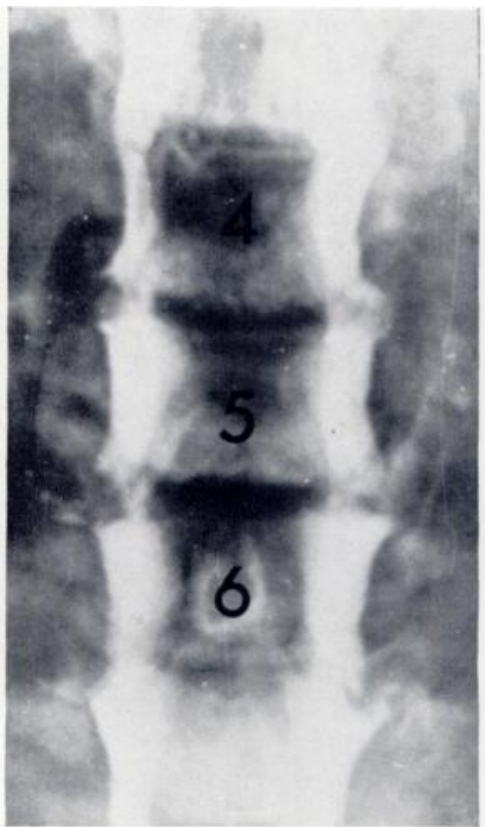

FIG. 4

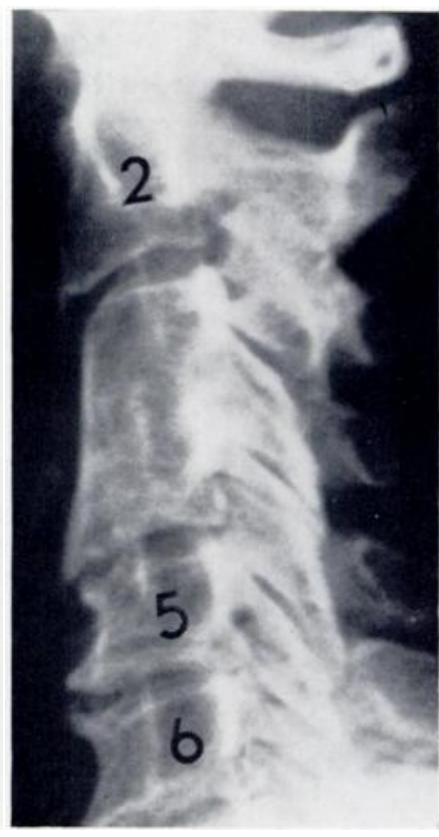

FIG. 5

Case 1. Figure 3-Lateral radiograph of cervical spine showing advanced degeneration at all levels. Figure 4 Cervical myelograph showing anterior bar formation between the fourth and fifth and the fifth and sixth cervical vertebrae. Figure 5-Lateral radiograph showing solid fusion between the third and fourth vertebrae. The patient was completely relieved of symptoms by a one-level fusion after the level of production of symptoms had been identified by discography.

and the fifth and sixth cervical vertebrae (Fig. 4). When the lower disc spaces were injected the patient kept stating that her usual pain was at a higher level. She was insistent on this until the disc between the third and fourth vertebrae was reached: then her symptoms were markedly and consistently reproduced. The remaining levels showed obvious degenerative change, but did not cause her symptoms. Her symptoms were dramatically relieved by anterior discectomy and fusion between the third and fourth vertebrae (Fig. 5). The patient gained weight and has remained free from pain over the two and a half years since operation.

\section{SELECTION OF TECHNIQUE}

In selecting the operative technique it is important that it should not distress the patient and allow adequate removal of the disc and relief of any nerve root pressure. It should give rigid immobilisation to the affected segment and ideally should maintain some degree of distraction at the involved level. It should achieve a high rate of solid bony fusion.

Three commonly used operative techniques are those of Robinson, Cloward, Bailey and Badgley (Fig. 6). The dowel (Cloward) type of graft is quite popular and has many advantages. We have questioned whether it is quite as rigid under side-to-side strain, and whether as much distraction can be obtained as when a block keystone type of graft is seated into a trough which is distracted to its full length. 
ANTERO-POSTERIOR

LATERAL

Right Vert. Left

A.

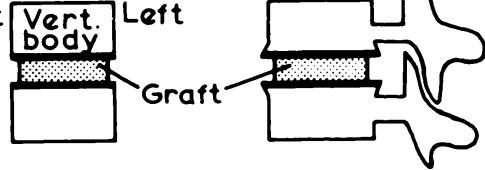

B.
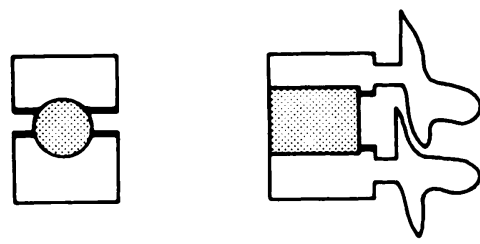

C.
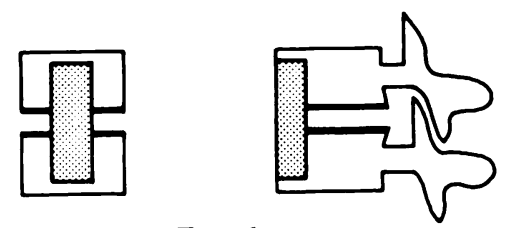

FIG. 6

Three common techniques of fusion: A Robinson; B Cloward; C Bailey and Badgley. (Reproduced by permission from the Journal of Bone and Joint Surgery, 44-A, 1962.)
We have favoured a block type of graft as initially recommended by Macnab in 1954. This has been modified to a keystone type of graft bevelled upwards and downwards, allowing it to lock into position when placed into a prepared defect with the neck under full distraction.

\section{TECHNIQUE}

Endotracheal anaesthesia is used. The ankles are strapped to the table and a sterile head halter is applied during the draping of the patient. A rightsided approach is used. A transverse skin incision is made along the line of the skin creases. After division of the platysma transversely, the strap muscles and viscera are retracted medially and the sternomastoid and great vessels laterally. A 26-gauge needle is inserted into the exposed disc, and radiographic proof of the exact level is obtained. A keystone square or rectangle of tissue is removed, bevelled upwards into the vertebra above and downwards into the vertebra below (Fig. 7). To allow the keystone defect to be cut precisely and safely, a set of special shouldered

chisels and osteotomes has been designed, each with a depth of 1.27 centimetres and of widths of $1 \cdot 27,1 \cdot 1$ and .95 centimetres (Fig. 8). ${ }^{*}$ Care should be exercised in cutting the sides of the defect with the chisel so that the cut does not extend outwards to each side excessively, but is in a true antero-posterior plane. In most instances a 1.27 centimetre square of tissue is removed for a onelevel fusion: occasionally in persons with a narrow cervical spine a smaller width is indicated. The disc material is completely removed with pituitary rongeurs and by curettage, care being taken to remove the disc tissue from posteriorly to anteriorly. The end stage of this is facilitated by having the anaesthetist apply traction to the head halter, thus opening up the disc space and allowing the removal to be carried well out to the neuro-central joints. The trough is deepened to the posterior cortex of the vertebrae (Fig. 9). This can usually be done satisfactorily by gentle manual curettage or it may be facilitated by an electric or gas-powered burr. The corners should be squarely cut. The length to which the square can be distracted into a rectangle is then measured by having the anaesthetist apply fairly forceful traction on the head halter. In most one-level fusions this amounts to at least three millimetres. A rectangular graft is obtained from the iliac crest and shaped to fit the trough. The ends are bevelled upwards and downwards to lock into place (Fig. 10). Experiments have suggested that the ideal locking angle of the bevel is between 14 and 18 degrees. With the neck

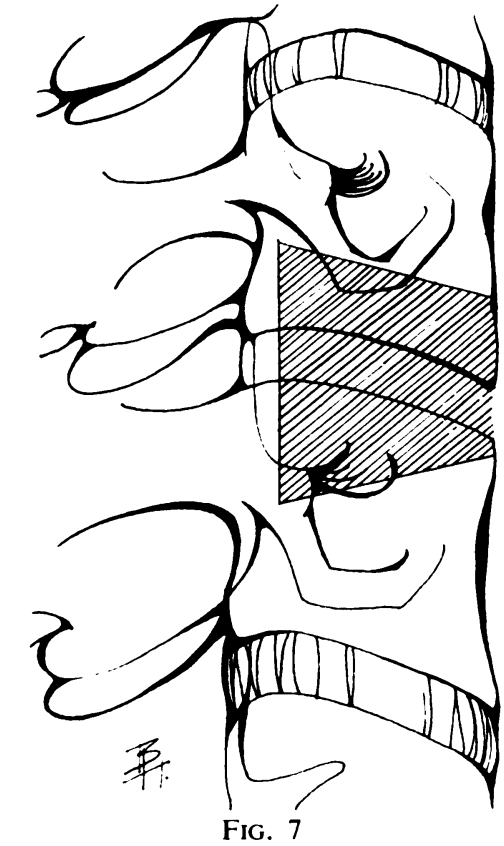

The principles of the keystone graft. The proper bevelling of the graft into the vertebra above and below is shown as well as the positioning of the graft, close to the posterior border of the vertebral bodies.

* The shouldered chisels and osteotomes are available through Down Bros. and Mayer \& Phelps Ltd., London, England; Niagara Falls, New York, United States of America; and Toronto, Canada. 


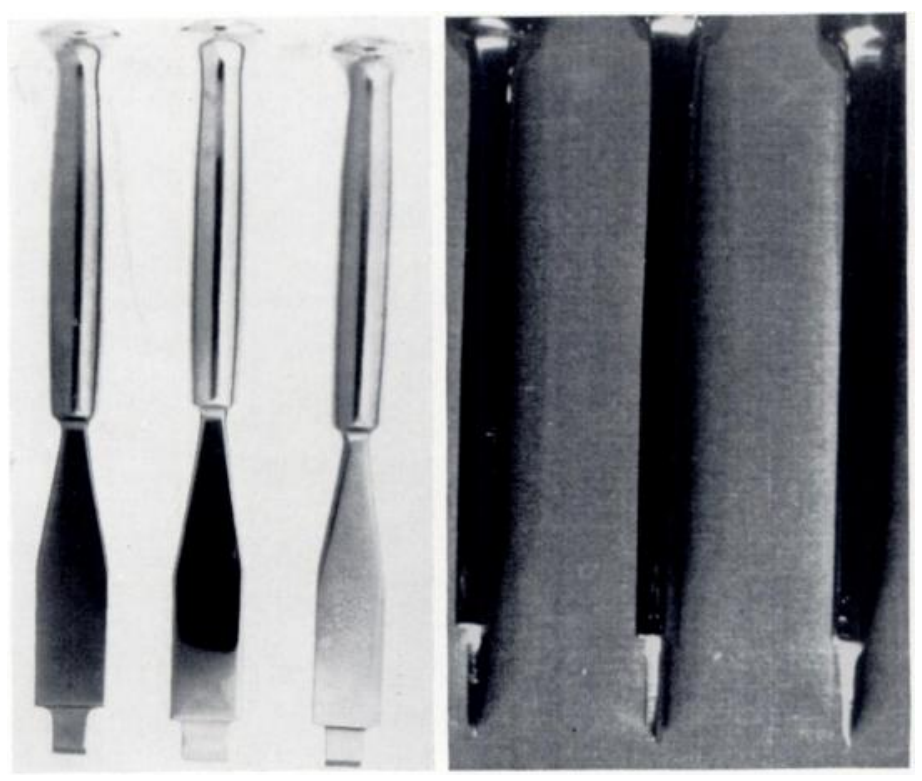

FIG. 8

The shouldered chisels designed by the senior author. Each has a constant depth of $1 \cdot 27$ centimetres, with widths of $1 \cdot 27,1 \cdot 1$ and .95 centimetres.

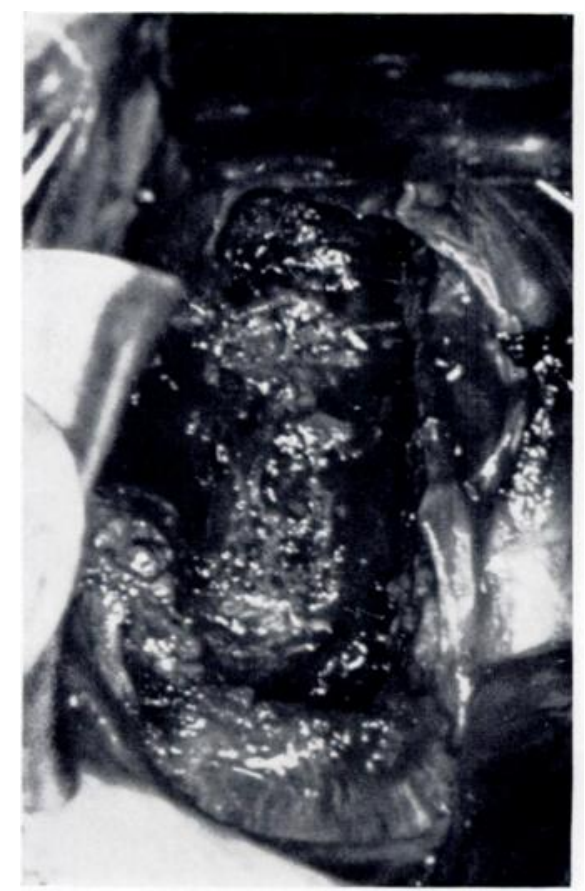

FIG. 9

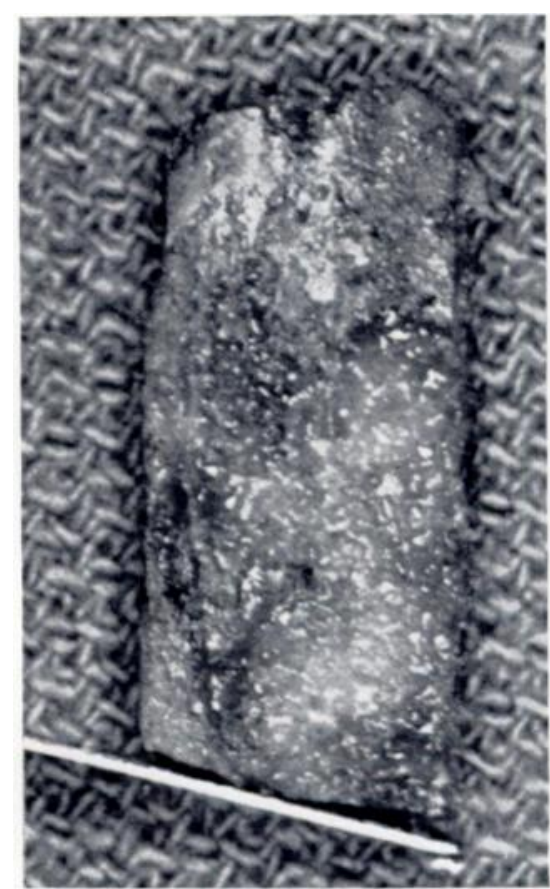

FIG. 10

Figure 9-Appearance at operation of the prepared defect bevelled upwards into the vertebra above and downwards into that below, and deepened to the posterior cortex of the vertebrae. Figure 10-The prepared graft with its keystone shape, made to a length greater than the initial defect to allow full distraction. 
in the fully distracted position obtained by forceful traction, the graft is driven into the defect and the traction released, locking it firmly into position, maintaining fixed distraction and immobilisation. When two levels are fused the trough and graft are extended through the intervening vertebra into the one above and below.

This technique has the advantage that if the initial placement is not exact the trough can always be extended to engage each vertebra adequately, whereas in the dowel technique if the drill is not directed perfectly it may give a poor

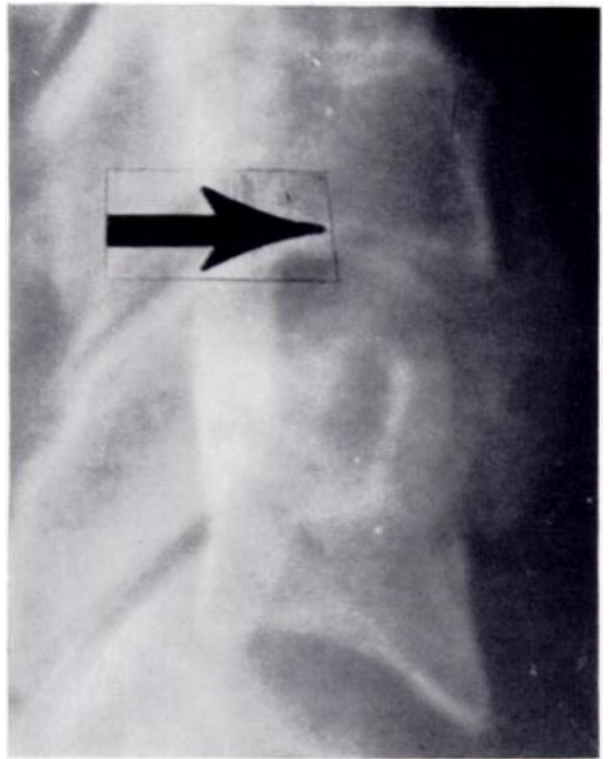

FIG. 11

Lateral radiograph showing inadequate purchase of the dowel graft in the upper vertebral body with the graft being partially extruded. purchase on the vertebra above, and there is not much that can be done about it (Fig. 11).

\section{MECHANICAL CONSIDERATIONS}

Surface area of graft-The surface area of a bone graft has an important relationship to revascularisation and bony union. When the surface area is calculated for the two types of grafts, cylindrical and rectangular, it is found that a rectangular graft has approximately 30 per cent more surface area than that of a cylindrical graft of comparable size. When these calculations are carried out for a twolevel fusion, the surface area is about 70 per cent more for a rectangular graft than if two separate cylindrical grafts are used.

Stability-A comparative study of keystone and dowel grafts was carried out in cadavers to test the stability of the grafts both in the vertical direction as related to flexion and extension movements, and in side-to-side movements. The specimens were dissected free of all muscle attachments, leaving the ligaments and discs intact. The two types of operation were carried out at different levels in different specimens. Specimens were prepared with the keystone procedure at one level and the dowel procedure at another, and then the levels were reversed to maintain consistency in the experiments (Fig. 12). The specimens were mounted in a stress machine and submitted to varying degrees of flexion and extension strain (Fig. 13). A constant minimal ejection force was applied to each graft in the form of an attached $\cdot 36$ kilogram weight to allow controlled cinephotographic recording. This was kept constant throughout the range of testing. Under the conditions of these experiments it was clearly shown that a keystone graft was more stable than a dowel graft. The dowel grafts were consistently extruded when a range of 20 to 25 degrees of extension was reached. The keystone grafts were not extruded until there was fracturing with complete disruption of the posterior elements of the spine.

Lateral stability was tested by inserting two electrodes, one in the graft and one in the vertebral body: these were connected to a battery cell through a flashbulb. The distance between the two electrodes was kept constant and was the width of a surgical scalpel blade. Slight movement between the graft and the vertebral body would thus allow the circuit to be completed. It was found that it required very little lateral bending stress to complete the circuit with the dowel graft. The keystone graft resisted more than four times the same lateral bending force without completion of the circuit, indicating absence of significant lateral bending motion. Position of the bone graft-Position has a bearing on the liability of the graft to extrusion. In theory it should be placed as close to the line of "zero velocity" as possible. Prepared specimens were bisected and the line of "zero velocity" was determined. It was found to 
pass through the origin of the nerve roots. For practical purposes the graft should be placed as close as possible to the posterior part of the vertebral body.

\section{CLINICAL STUDY}

At the Toronto East General and Orthopaedic Hospital this operation was first used in April 1959 and since then 154 patients have been operated upon. Only the first eighty-four of these patients operated on before December 1966 were included in this study (Table I). There were forty-six female and thirty-eight male patients aged from twenty to seventy years. More than half (forty-seven patients) had a history of injury to the cervical spine, thirtyeight having been involved in traffic accidents. Fourteen patients suffered further severe injury after fusion, and six of these required a second operation at a different level. The duration of pain before operation varied from three months to twenty-seven years, with an average of five years.

The main indications for operation were: 1) chronic neck pain which could not be controlled with adequate conservative treatment; 2) chronic neck pain with obvious neurological signs; and 3) cord compression with long tract signs (Table II). The follow-up period varied from one to eight and

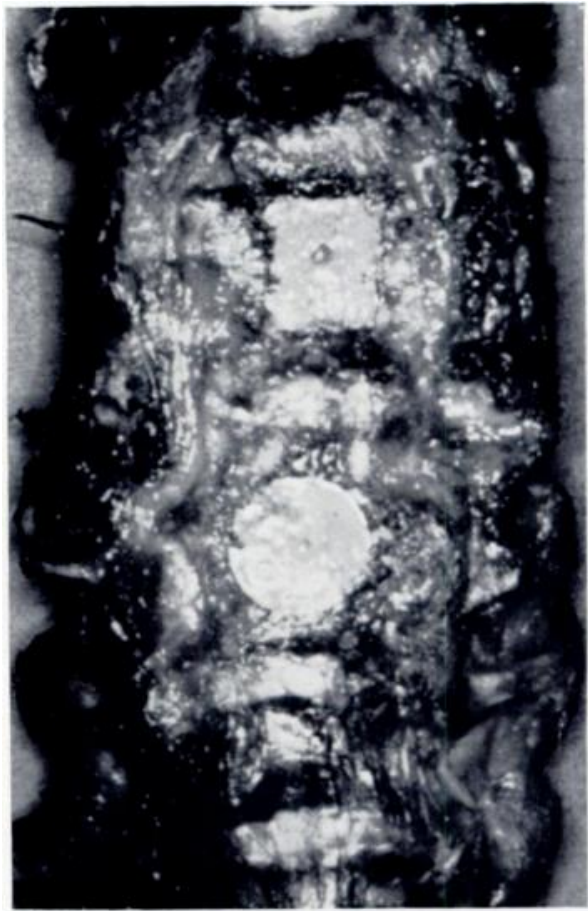

FIG. 12

A prepared specimen in which the muscular attachments have been removed but in which the ligaments and discs have been left intact. A keystone graft has been inserted at the upper level and a dowel graft at the lower level with one intervening intervertebral disc left intact. a half years, the average being thirty-four months. The levels fused are shown in Table III: the joint fused most often was that between the fifth and sixth vertebrae, the next in order of frequency being those between the sixth and seventh

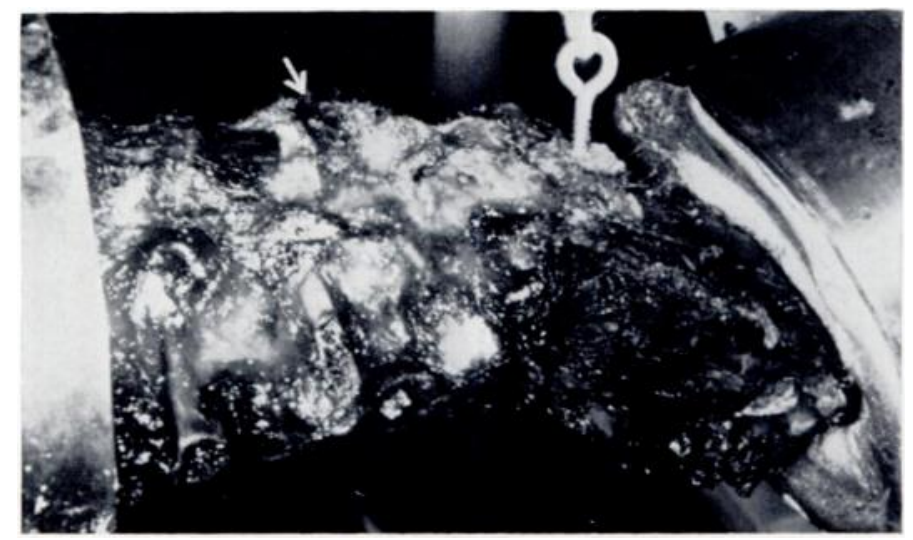

Fig. 13

The specimen under test. The dowel graft (arrowed) extruded when a little over 15 degrees of extension was produced. The keystone graft is still in place: it did not extrude until there was complete disruption of the posterior elements of the spine.

and the fourth and fifth vertebrae. Forty-three patients had one level fused and thirty-seven patients had two levels fused. Four patients had three levels fused after secondary injury necessitating a second operation at a level adjacent to the previous fusion.

VOL. 51 B, NO. 2, MAY 1969 
All eighty-four patients were available for review. Eighty-three were brought back for further evaluation or were visited and assessed elsewhere. Arrangements were made for one patient to be examined at another centre by another observer. Sixty-eight patients were treated with the keystone technique, and seventeen with the dowel technique. One patient had one level fused with the keystone graft and another with a Cloward graft. The clinical results were classified separately for the keystone and dowel procedures (Tables IV and V) which are briefly: excellent, no complaints and no handicap; good, intermittent relevant discomfort, not significantly interfering with work; satisfactory, subjective improvement but physical activities significantly limited; poor, unimproved or worse (Odom, Finney and Woodhall 1958). The results appeared better with the keystone technique, there being 80.8 per cent of excellent or good results as opposed to 64.8 per cent for the dowel procedure. It is important to note that the keystone group had a preponderance of multiple level fusions, there being four threelevel, thirty-six two-level and only twenty-eight one-level fusions. The three poor results were all in multiple level fusions, there being no poor results in single level fusions. The dowel

TABLE I

Clinical Material

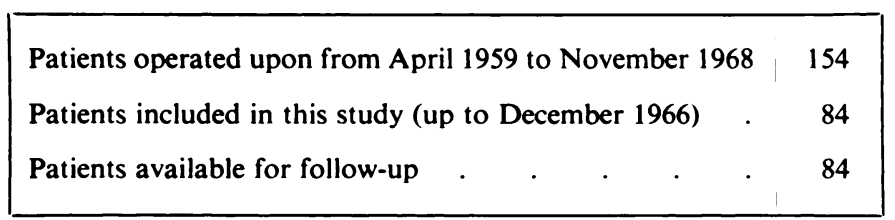

TABLE II

INDICATIONS FOR OPERATION

\begin{tabular}{|l|c|}
\hline \multicolumn{1}{|c|}{ Clinical features } & Number of cases \\
\hline Chronic neck pain & 30 \\
\hline $\begin{array}{l}\text { Neck pain and objective } \\
\text { neurological findings }\end{array}$ & 51 \\
\hline Long tract signs . & 2 \\
\hline $\begin{array}{l}\text { Fracture-dislocation of } \\
\text { cervical spine }\end{array}$ & 1 \\
\hline Total $\cdot$ & 84 \\
\hline
\end{tabular}

TABLE III

LEVELS FUSED

\begin{tabular}{|c|c|}
\hline Level & Number of cases \\
\hline C.5-6 & 66 \\
\hline C.6-7 & 27 \\
\hline C.4-5 & 24 \\
\hline C.3-4 & 10 \\
\hline C.2-3 & 1 \\
\hline Total & 128 (in 84 patients) \\
\hline
\end{tabular}

group were predominantly one-level procedures, there being only one two-level procedure. There were three poor results in this group. It is recognised that the number of patients in the dowel series is small and the results should be compared with other series in the literature.

The complications encountered are noted in Table VI. There was no incidence of wound infection. There was no involvement of major neck vessels and there were no operative deaths. There was no involvement of the recurrent laryngeal nerve, no perforations of the oesophagus or trachea and no incidence of mediastinitis or pneumothorax. There were three cases of non-union, in all of which the clinical results were bad; all occurred with the dowel graft procedure. The keystone graft series, with its higher incidence of multiple level fusions, had no incidence of non-union. This apparent high incidence of successful fusion with the keystone procedure is even more significant when it is compared with results in other series 
TABLE IV

Clinical Results-Keystone Technique (Twenty-eight one-level fusions; thirty-six two-level fusions; four three-level fusions)

\begin{tabular}{|c|c|c|c|}
\hline \multicolumn{2}{|c|}{ Result } & Number of patients & One level \\
\hline \multicolumn{2}{|c|}{ Excellent or good } & $55(80.8$ per cent $)$ & 25 \\
\hline Fair. & . & $10(15$ per cent $)$ & 3 \\
\hline Poor & . & $3(4 \cdot 2$ per cent $)$ & Nil \\
\hline & . & 68 & \\
\hline
\end{tabular}

TABLE V

Clinical Results-Cloward Procedure (Sixteen one-level fusions; one two-level fusion)

\begin{tabular}{|c|c|}
\hline \multicolumn{1}{|c|}{ Result } & Number of patients \\
\hline Excellent or good & $11(64.8$ per cent $)$ \\
\hline Fair . $\cdot$ & $3(17 \cdot 6$ per cent $)$ \\
\hline Poor . $\cdot$ & $3(17 \cdot 6$ per cent $)$ \\
\hline Total . & 17 \\
\hline
\end{tabular}

TABLE VI

Complications

\begin{tabular}{|c|c|c|c|}
\hline \multicolumn{3}{|c|}{ Complication } & \multirow{2}{*}{$\frac{\text { Number of cases }}{3 \text { (all Cloward) }}$} \\
\hline Non-union & . & . & \\
\hline Ejection of bone graft & · & . & $2\left\{\begin{array}{l}1 \text { keystone } \\
1 \text { Cloward }\end{array}\right.$ \\
\hline Painful iliac scar (1 severe) & & . & 8 \\
\hline Iliac wound haematoma & . & . & 4 \\
\hline Iliac wound infection . & . & . & 2 \\
\hline $\begin{array}{l}\text { Secondary closure iliac w } \\
\text { suture removal). }\end{array}$ & & to early & 1 \\
\hline Severe operative bleeding & . & . & 1 \\
\hline Phlebitis and pulmonary in & far & covered) & 1 \\
\hline Contracture of vertical scar & $(\mathrm{r}$ & Z-plasty) & 1 \\
\hline Swallowing difficulty. (Ba & ar & normal) & 2 \\
\hline
\end{tabular}

vol. 51 B, NO. 2, MAY 1969 


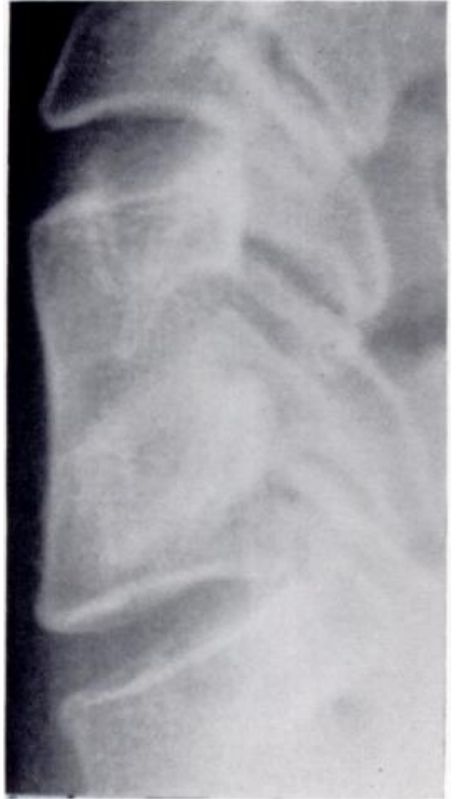

FIG. 14

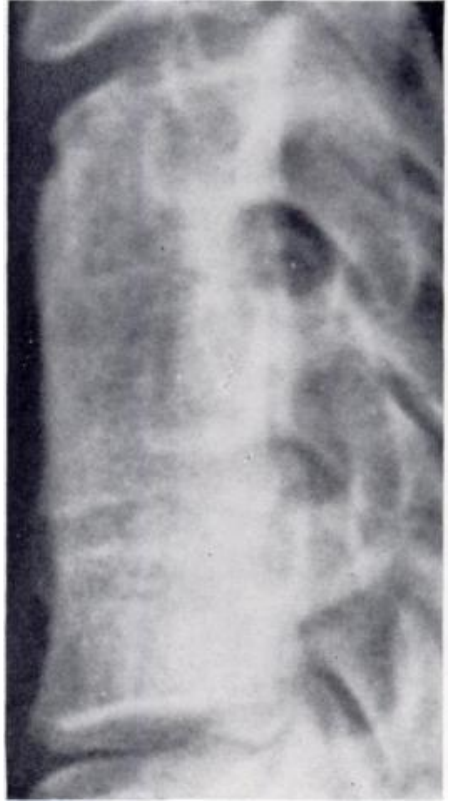

FIG. 15

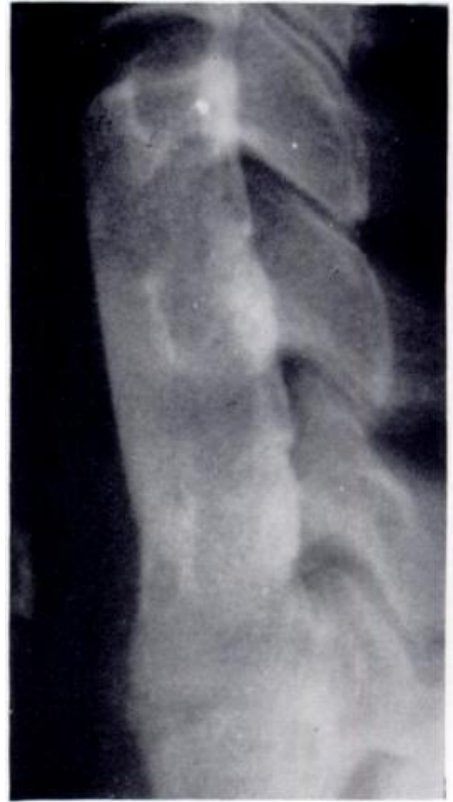

FIG. 16

Radiographs showing one, two and three-level fusions, from six to nine months after operation. In each instance there has been solid fusion with trabeculae continuous from one vertebra to the next.

showing a pseudarthrosis rate of 15 per cent for one and two-level fusions, and 46 per cent for three-level fusions (Connolly, Seymour and Adams 1965). It is felt that the high rate of fusion obtained with the keystone graft is related to the type of graft, its method of seating, its depth of penetration, its large surface area and the fact that cancellous bone of the adjacent vertebrae is in contact with the graft above and below (Figs. 14 to 16). There were two ejections of the graft. One occurred in the keystone series $(1.5$ per cent $)$ and one in the dowel group (5.8 per cent). A high incidence of extrusion of the graft has been reported in the literature, varying from 3 to 14 per cent (Gregory 1966). It was almost negligible in the keystone series. The iliac wound requires attention, because in eight patients the scar was painful. It has been observed that if the incision is placed about three centimetres below the iliac crest it is not so painful as when it is placed over the prominence of the crest.

We believe that there are two main causes of continued symptoms in spite of satisfactory fusion. The first is failure to select the correct site; in our early cases discography was done under anaesthesia and this led to errors. The second cause we believe to be degenerated discs beyond the area of fusion; some followed secondary injuries, and of those some were relieved by later fusion at the new level.

\section{DISCOGRAPHY: TECHNIQUE AND INTERPRETATION OF RESULTS}

The approach is simple: it is that followed in the operative approach. The neurovascular bundle is displaced laterally with the pads of the fingers and the pharyngo-oesophago-tracheal bundle is displaced medially with the nails of the same fingers, so that the tips of the fingers are separated from the cervical vertebrae by skin and a minimal amount of soft tissue. A 24 gauge spinal needle can be passed directly to the surfaces of the vertebrae and "walked" up and down without the need for an outer needle and without losing the sensitivity of touch. The different resistance of the disc is easily appreciated and the puncture can be performed. Usually four discs should be examined. The position of the needle tips must be seen in two planes: screening in two planes with image intensification is a great time saver. 
As a rule, the insertion of the needles is neither difficult nor unduly painful. Difficulties may arise in the patient with a "bull neck" or in the case of deformity or if the discs between the second and third cervical or between the seventh cervical and first thoracic vertebrae are being punctured. The thyroid gland is traversed by the needle during a puncture at the latter level; this probably occurs in punctures at other levels too, but no complications have been reported.

The painful part of the procedure, both for the patient and for the radiologist, is the repeated injection of saline to reproduce the symptoms. The importance of repeating the injections and of altering the sequence without the patient knowing the level being injected cannot be overemphasised. Only if a response is constant can the result be considered to be of diagnostic value.

Recently the procedure has been performed with the help of amytal narcosis: the patient suffers much less and the result is of equal diagnostic value. In a few cases the disc shown to be the site of origin of symptoms has been injected with 0.5 millilitre of 2 per cent Lidocaine Hydrochloride. This has produced prompt disappearance of all pain including that present before discography. Both these techniques need further study before their value can be assessed.

Interpretation-There has been controversy about the interpretation of the radiographic appearance of the discs after the injection of the contrast medium. Almost invariably all the discs examined are degenerate and most have herniated; one must therefore admit that the radiographic appearance of the disc is of little diagnostic value. The value of discography is, therefore, not as an anatomical but rather as a functional study.

TABLE VII

LeVels of Fusion in ThiRTY-eight Patients (One had fusion between the third and fourth vertebrae and later between the fifth and sixth)

\begin{tabular}{|c|c|}
\hline Level & Number of patients \\
\hline $2-3$ & 1 \\
\hline $3-4$ & 8 \\
\hline $4-5$ & 4 \\
\hline $5-6$ & 9 \\
\hline $6-7$ & 5 \\
\hline $7-1$ & 0 \\
\hline $2-3$ and 3-4 & 1 \\
\hline $3-4$ and $4-5$ & 0 \\
\hline $4-5$ and 5-6 & 5 \\
\hline $5-6$ and 6-7 \\
\hline $6-7$ and 7-1 \\
\hline
\end{tabular}

How valuable is discography in the operative treatment of degenerative disc disease of the cervical spine? To answer this question, forty patients admitted consecutively for operation over a period of eighteen months were reviewed. To compare the value of clinical study, myelography and discography, it was necessary to choose some method of assessment, because the anatomical proof that one obtains in the case of the lumbar spine is not available in that 
of the cervical spine. The result of operation was used as the guide: if the patient was relieved of his symptoms by the fusion of two vertebrae it was considered that the disc between them was the one responsible for the symptoms. Reference was then made to the level selected by the clinical assessment or by the myelograph.

Of the forty patients, two refused treatment, three had no discography, and four had no myelography, so that thirty-one patients had clinical, myelographic and discographic assessment. The clinical decision on the level of disease was correct in nine patients, and was incorrect in thirteen. In nine patients there was too much or too little evidence about root involvement for a definite level to be established. Myelographic assessment was correct in seven patients and incorrect in fourteen (including seven negative results). In ten, either too many levels were involved or the findings were only vaguely suggestive. Unfortunately the myelographic and clinical errors tended to occur in the same patients and often the only evidence not in accord was that obtained by discography. The level operated on was that indicated by discography (Table VII).

A good result was obtained in thirty of the thirty-one patients. That is, there was immediate lessening of symptoms and all pain was gone in a week after surgery. The one poor result occurred in a patient with radiographic, myelographic and objective clinical evidence of affection of the left sixth cervical nerve and with pain high in the neck. Discography indicated that the pain in the neck was arising from the disc between the third and fourth cervical vertebrae, but the root pain could not be reproduced. A fusion between the third and fourth vertebrae relieved the neck pain but not the root pain. A fusion between the fifth and sixth vertebrae was then done but the patient, although somewhat improved, still had some residual root pain.

The other seven patients who did not have full radiological investigation were operated upon and obtained good results.

Until a good theory is proposed to explain pain production from cervical disc disease and until a method of investigation is outlined on this principle, diagnostic disc puncture is the best method for investigation of disease of the cervical discs.

\section{SUMMARY}

1. A series of 154 patients who underwent anterior cervical discectomy and fusion has been studied. A detailed analysis of the first eighty-four patients who have been observed for periods of from one to eight and a half years is described. In sixty-eight patients the fusion was done with a keystone type of graft, in seventeen by a dowel (Cloward) graft.

2. Despite a preponderance of multiple level fusions in the keystone series, clinically better results ( 80.8 per cent excellent or good) were found in this group than in the dowel group (64.8 per cent excellent or good).

3. A biomechanical study has indicated the keystone graft to be more stable than a dowel graft under flexion and extension strains as well as lateral bending strain. The graft is more stable the closer it is to the line of "zero velocity."

4. The three cases of non-union all occurred in the dowel group. The high incidence of fusion with the keystone technique is considered to be related to the type of graft, its method of seating, its depth of penetration, its larger surface area and the fact that raw cancellous bone of the adjacent vertebral bodies is in contact with the graft above and below.

We would like to thank $\operatorname{Dr} T$. W. Barrington for permission to include his patients in this series. We are grateful to Professor J. S. Thompson and Professor R. G. MacKenzie of the Department of Anatomy, University of Toronto, for making available the facilities to carry out the biomechanical study. We are greatly indebted to Mr Henry Garside for his biomechanical consultations and assistance with the stress machine at the Research Laboratory, St Joseph's Hospital, Toronto, Canada. We are indebted to the Toronto East General and Orthopaedic Hospital Research Foundation for their assistance in enabling this study to be carried out. 


\section{REFERENCES}

Bailey, R. W., and Badgley, C. E. (1960): Stabilization of the Cervical Spine by Anterior Fusion. Journol of Bone and Joint Surgery, 42-A, 565.

Butr, W. P. (1963): Lumbar Discography. Journal of the Canadian Association of Radiologists, 14, 172.

Butr, W. P. (1966): Discography-Some Interesting Cases. Journal of the Canadian Association of Radiologists, $17,167$.

Cloward, R. B. (1958): The Anterior Approach for Removal of Ruptured Cervical Disks. Journal of Neurosurgery, 15, 602.

Cloward, R. B. (1959): Vertebral Body Fusion for Ruptured Cervical Discs: Description of Instruments and Operative Technic. American Journal of Surgery, 98, 722.

Cloward, R. B. (1962): New Method of Diagnosis and Treatment of Cervical Disc Disease. Clinical Neurosurgery, 8, 93.

Connolly, E. S., Seymour, R. J., and Adams, J. E. (1965): Clinical Evaluation of Anterior Cervical Fusion for Degenerative Cervical Disc Disease. Journal of Neurosurgery, 23, 431.

Gregory, C. F. (1966): Panel Discussion. Spinal Fusion through the Anterior Approach. Clinical Congress, American College of Surgeons, San Francisco, U.S.A.

Macnab, I. (1954): Personal communication.

Odom, G. L., Finney, W., and Woodhall, B. (1958): Cervical Disk Lesions. Journal of the American Medical Association, 166, 23.

Robinson, R. A., and Smith, G. W. (1955): Anterolateral Cervical Disc Removal and Interbody Fusion for Cervical Disc Syndrome. Bulletin of the Johns Hopkins Hospital, 96, 223.

Robinson, R. A., and Southwick, W. O. (1960): Surgical Approaches to the Cervical Spine. Instructional Course Lectures. The American Academy of Orthopaedic Surgeons Incorporated, 17, 299.

Robinson, R. A., Walker, A. E., Ferlic, D. C., and Wiecking, D. K. (1962): The Results of Anterior Interbody Fusion of the Cervical Spine. Journal of Bone and Joint Surgery, 44-A, 1569.

Scoville, W. B. (1966): Types of Cervical Disk Lesions and their Surgical Approaches. Journal of the American Medical Association, 196, 479. 